\title{
Molecular Docking Evaluation of Some Natural Phenolic Compounds as Aldose Reductase Inhibitors for Diabetic Complications
}

\author{
AJMER SINGH GREWAL*, NEELAM SHARMA, SUKHBIR SINGH AND \\ SANDEEP ARORA \\ Chitkara College of Pharmacy, Chitkara University,Rajpura, Patiala,140401, Punjab, \\ India
}

*Email: ajmergrewal2007@gmail.com

Received: May 15, 2017 I Revised: June 20, 2017 I Accepted: August 07, 2017

Published online: Nov. 02, 2017

The Author(s) 2017. This article is published with open access at www.chitkara.edu.in/publications

Abstract The enzyme aldose reductase (AR) is a member of aldoketoreductase super-family which catalyzes the formation of sorbitol from glucose through polyol pathway of glucose catabolism. Reduced sorbitol production via polyol pathway due to AR inhibition is a target of choice for controlling major complications of diabetes. Epalrestat is the only commercially available inhibitor of AR till date,thus, there is a great need to search for more economical, nontoxic and safer inhibitors of AR enzyme. Flavonoids, the polyphenol compounds in plants have been reported for inhibitory effects against AR. The objective of this study is to explore the binding modes of natural phenolic compounds with AR to design safer natural drugs as alternatives to synthetic drugs. We conducted a molecular docking study on some natural phenolic compounds with AR enzyme in complex with the synthetic inhibitor. The overlay of the docked pose of the selected natural phenols with the ARreference inhibitor complex showed that the selected natural compounds have the similar binding pattern with the active site residues of the enzyme as that of co-crystallized inhibitor. The results of docking study showed the best binding affinity of AR with that of 2-(4-hydroxy-3-methoxyphenyl) ethanoic acid and butein, having the lowest binding free energy of $-9.8 \mathrm{kcal} / \mathrm{mol}$ and $-9.7 \mathrm{kcal} / \mathrm{mol}$, respectively. This information can be utilized to design potent, economical and non-toxic natural AR inhibitors from natural phenols for the therapeutics of diabetic complications.

Journal of Pharmaceutical Technology, Research and Management

Keywords: Aldose Reductase, AR Inhibitors, Diabetic Complications, Vol-5, No-2, Flavonoids, Molecular Docking, Phenolic compounds, Polyol Pathway.

November 2017 pp. $135-148$ 
Grewal, A.S.

Sharma, N.

Singh, $\mathrm{S}$.

Arora, S.

\section{INTRODUCTION}

Diabetes mellitus (often called as diabetes) is a cluster of metabolic conditions due to defect in insulin secretion, insulin action, or both resulting in prolonged hyperglycemia and defective metabolism of food. According to etiological classification, Type 1 diabetes (also called as insulin dependent diabetes mellitus or juvenile-onset diabetes, occurs due to defect in the $\beta$-cells of pancreas, resulting in lack of insulin) and Type 2diabetes (also called as noninsulin dependent diabetes mellitus or adult-onset diabetes, occurs due to defect in insulin action)are two most important types of diabetes (American Diabetes Association, 2014; Grewal et al., 2014). As per the latest data from International Diabetes Federation, in 2013 there were 382 million diabetic patients, and in 2035 the number of diabetic patients may approach 600 million. Diabetes is the major contributor to the mortality worldwide, especially in the developing countries and the latest figures pointed out diabetes as a key obstacle in the overall development worldwide. Diabetes has become the major health problem worldwide, and has been pointed out as crucial importance in community health due to various complications linked with it(International Diabetes Federation, 2013; Wild et al., 2004; Olokoba et al., 2012; Mohan \& Anbalagan, 2013). The main effect of lack of insulin or insulin resistance is the defective metabolism of glucose in the cells of body resulting in increased glucose concentration in blood, and increased metabolism of fats and proteins(Kohei, 2010). The diabetic complication result due to longlasting increased blood glucose levels resulting in injury to blood vessels and peripheral nerves. The major diabetic complications are classified as microvascular (diabetic neuropathy, nephropathy, retinopathy, and cataracts) and macro vascular complications (defects in cardiovascular and cerebrovascular system) (Cade, 2008). The various mechanisms had been proposed for diabetic complications including polyol pathway, larger production of advanced glycation end products, augmented production of diacylglycerol due to hyperglycemia, altered catabolism of extra glucose through hexosamine pathway and defect in antioxidant mechanism due to hyperglycemia. The polyol pathway is the most accepted mechanism of crucial significance for the pathogenesis of complications of diabetes. The activated polyol pathway leads to enlarged buildup of sorbitol in cells causing osmotic tension on the cells which harms the proteins of cell membrane via various oxidative mechanisms (Forbes\& Cooper, 2013).

Aldose Reductase (AR) is a member of the aldo-ketoreductase superfamily of enzymes which catalyzes the formation of sorbitol from glucose, the very first and most important rate-determining reaction of the polyol pathway 
(Yabe-Nishimura, 1998; Oates, 2008). Under normal conditions glucose is catabolized via glycolysis and Kreb's cycle leading to formation of building blocks and energy for cellular functions.

In case of hyperglycemia, higher glucose concentration stimulates AR resulting in metabolism of glucose by activated polyol pathway. AR reduces that glucose to sorbitol, which is later oxidized to fructose. In the process of reducing high intracellular glucose to sorbitol, AR consumes the cofactor NADPH (an important co-factor involved in production of an important antioxidant, glutathione, resulting in decreased glutathione levels). Osmotic stress due to accumulation of extra sorbitol and oxidative stress due to decrease in NADPH/NADP ${ }^{+}$ratio and reduced $\mathrm{NAD}^{+}$leads to reduced cellular antioxidant capacity. Increased production of sorbitol catalyzed by AR in polyol pathway accumulates in cells and is difficult to diffuse through the cell membranes, which increases osmotic stress to cells leading to the development of diabetic complications. The accumulation of sorbitol through increased activity of AR in lens, retina, and sciatic nerves result in retinopathy, neuropathy, and nephropathy, respectively (Forbes\& Cooper, 2013; Brownlee, 2001; Chung \& Chung, 2005). The polyol pathway can be targeted by inhibiting the enzyme AR resulting in the reversal of the osmotic stress caused by activated polyol pathway. Thus, reduction of the polyol pathway by AR inhibitors has been a potential therapeutic target in the treatment and prevention of diabetic complications. Numerous AR inhibitors have been advanced as drug candidates for the treatment and prevention of diabetic complications (Oates, 2008; Brownlee, 2001; Suzen \& Buyukbingol, 2003; Cumbie \& Hermayer, 2007).The AR inhibitors developed vary structurally including carboxylic acid derivatives, spirohydantoins and related cyclic amides, nitromethane derivatives, sulfonamides, thiazolidinediones, benzodiazepines, and phenolic derivatives (related to benzopyran-4-one and chalcone). Even though numerous clinical trials for the treatment of diabetic complications have been conducted over the past two decades with synthetic compounds, pharmacokinetic problems connected to these AR inhibitors, together with the length of trials, have resulted in the lack of observed efficacy (Jain et al., 2012; Grewal et al., 2016). Among these AR inhibitors, epalrestat is the only commercially available inhibitor till date. Thus, there is still an urgent need for new and safe AR inhibitors. Several potent inhibitors of AR from natural sources have been reported which are obtained from terrestrial, microorganism, and marine sources for their role in the treatment and prevention of diabetic complications. AR inhibitors obtained from natural sources include flavonoids and phenolic compounds,alkaloids, terpenoids, coumarin
Molecular Docking Evaluation of Some

Natural Phenolic

Compounds as

Aldose Reductase Inhibitors for Diabetic Complications 
Grewal, A.S. Sharma, N. Singh, S. Arora, S.

derivatives, and vitamin C (Grewal et al., 2016; Fuente \& Manzanaro, 2003; Nakai et al., 1985).Numerous flavonoids like rutin, kaempferol, quercetin, and quercetrin had shown excellent anti-diabetic potential by AR inhibition (Lee et al., 2015; Zhang et al., 2016). Some natural phenolic compounds were chosen for the docking study from the recent literaturehaving potent AR inhibitory activity including nepetin (Tomás-Barberán et al, 1986), epicatechingallate (Murara et al., 1994), Capillarisin (Okada et al., 1995), isorhamnetin-3,7-disulfate (Haraguchi et al., 1996), Luteolin (Yoshikawa et al., 1999), Protocatechualdehyde (Goodarzi et al., 2006), Davidigenin (Logendra et al., 2006), curcumin (Muthenna et al., 2009), 2-(4-hydroxy-3methoxyphenyl)ethanoic acid (Kato et al., 2006), Quercetin (Chethan et al., 2008), butein (Lee at al., 2008), desmethylanhydroicaritin (Jung et al., 2008) and semilicoisoflavone B (Lee et al., 2010).

The aim of this study is the in silico evaluation of selected natural phenolic compounds in order to establish the structural basis of their AR inhibitory activity and to investigate the binding modes of the selected compounds in active site of AR to design safer natural drugs as alternatives to synthetic drugs using molecular docking.

\section{EXPERIMENTAL}

Molecular docking was performed for the selected natural phenolic compounds in the binding site of AR protein in AutoDockVina (Trott \& Olson, 2010) and the graphical user interface, AutoDock Tools (Morris et al., 2009) installed on Windows 7 computer.

\subsection{Preparation of Ligand Molecules}

The 2-D chemical structures of the ligands were prepared by MarvinSketch (Marvin 15.9.21,2015, ChemAxon) and converted to 3-D by Frog2 server based on a graph decomposition of the compounds coupled with an identification of the stereo-centres for which the chirality is unspecified (Miteva et al., 2010). The ligands were converted to PDBQT files from MOL format using AutoDock Tools.

\subsection{Preparation of Protein Molecule}

After assessing a numbers of co-crystallized structures of AR protein available in the RCSB protein data bank (http://www.rcsb.org/pdb), the best ligand bound complexes (PDB entry: 4LBS) was selected with complexes having maximum resolution and best binding interactions between ligands and 
proteins. The PDB files of the target protein was edited using PyMOL (The PyMOL Molecular Graphics System, Version 1.7.4.5 Edu, Schrödinger, LLC.) by removing complexed inhibitor, all the water molecules as well as all noninteracting ions. The PDBQT file of AR proteins was generated from the PDB files using AutoDock Tools and all the polar hydrogen atoms were added to the protein molecule.

\subsection{Preparation of Configuration Files}

The "Grid" of AutoDock Tools was used for calculating the grid parameters and all the data regarding target protein, ligand, grid size and geometry were saved in TXT file. The grid size was set to $32 \times 32 \times 32 \mathrm{xyz}$ points with grid spacing of $0.375 \AA$ and grid center was designated at dimensions ( $\mathrm{x}, \mathrm{y}$, and $\mathrm{z}$ ): $9.568,0.111$, and 0.097 . The exhaustiveness was set at 8 and scoring grid was calculated from the ligand structure to reduce the computation time.

\subsection{Docking Method}

The reference ligand, (2-((4-bromo-2,6-difluorobenzyl)carbamoyl)-5chlorophenoxy) acetic acid was docked in the active site of target proteins and compared with that of the co-crystallized inhibitor of AR (PDB ligand of 4LBS) for determining the accuracy of the docking protocol. The prepared ligand molecules were docked in the active site of the refined AR model utilizing AutoDockVina and scored by using scoring function. The binding free energy $(\Delta \mathrm{G}, \mathrm{kcal} / \mathrm{mol})$ for each ligand was reported in log file. PyMOL was utilized for the analysis of the binding interactions (including H-bond and hydrophobic interactions) of the ligands in the active site of target proteins.

\section{RESULTS AND DISCUSSION}

The names and chemical structures of the natural phenolic compounds selected for the molecular docking study are presented in Table 1 along with their source and reported AR inhibitory activity in terms of $\mathrm{IC}_{50}$ value (concentration causing 50\% inhibition of the AR activity). In silico studies were performed to explore the affinity and binding interactions of the selected natural phenolic compounds in the active site of AR protein (PDB entry: 4LBS). The reference ligand was docked into the active site of AR protein; and the docked reference inhibitor of AR produced a similar binding pattern and superposition on the binding mode of co-crystallized inhibitor with $\Delta \mathrm{G}$ of $-9.2 \mathrm{kcal} / \mathrm{mol}$ validating accuracy of docking methodology.
Molecular Docking Evaluation of Some

Natural Phenolic

Compounds as

Aldose Reductase Inhibitors for Diabetic Complications 
Grewal, A.S. Sharma, N. Singh, $S$. Arora, S.
Table 1: Structures of natural phenolic compounds selected for docking study with their source and reported AR inhibitory activity.

\begin{tabular}{|c|c|c|c|}
\hline Comp. & Name & Chemical structure & Remarks \\
\hline 1 & Nepetin & & $\begin{array}{l}\text { Obtained from } \\
\text { Eupatorium } \\
\text { ballotaefolium with } \\
\text { 95\%AR inhibition }\end{array}$ \\
\hline 2 & Epicatechingallate & & $\begin{array}{c}\text { Obtained from green } \\
\text { tea }(\text { Camellia sinensis }) \\
\text { leaves with } \mathrm{IC}_{50}=38 \mu \mathrm{M}\end{array}$ \\
\hline 3 & Capillarisin & & $\begin{array}{c}\text { Obtained from } \\
\text { Artemisiae capillaris } \\
\text { with } \mathrm{IC}_{50}=0.22 \mu \mathrm{M}\end{array}$ \\
\hline 4 & $\begin{array}{l}\text { Isorhamnetin-3,7- } \\
\text { disulfate }\end{array}$ & & 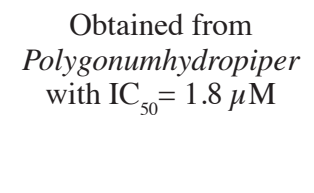 \\
\hline 5 & Luteolin & & $\begin{array}{l}\text { Obtained from } \\
\text { Chrysanthemum } \\
\text { indicum } \\
\mathrm{IC}_{50}=0.45 \mu \mathrm{M}\end{array}$ \\
\hline 6 & Protocatechualdehyde & & $\begin{array}{c}\text { Obtained from } \\
\text { Ganodermaapplanatum } \\
\mathrm{IC}_{50}=0.7 \mu \mathrm{M}\end{array}$ \\
\hline 7 & Davidigenin & & $\begin{array}{l}\text { Obtained from } \\
\text { Artemisiadracunculus } \\
\text { with } \mathrm{IC}_{50}=12.70 \mu \mathrm{M}\end{array}$ \\
\hline 8 & Curcumin & $\mathrm{OCH}_{3}$ & $\begin{array}{l}\text { Obtained from Curcuma } \\
\text { longawith } \mathrm{IC}_{50}=6.8 \mu \mathrm{M}\end{array}$ \\
\hline
\end{tabular}




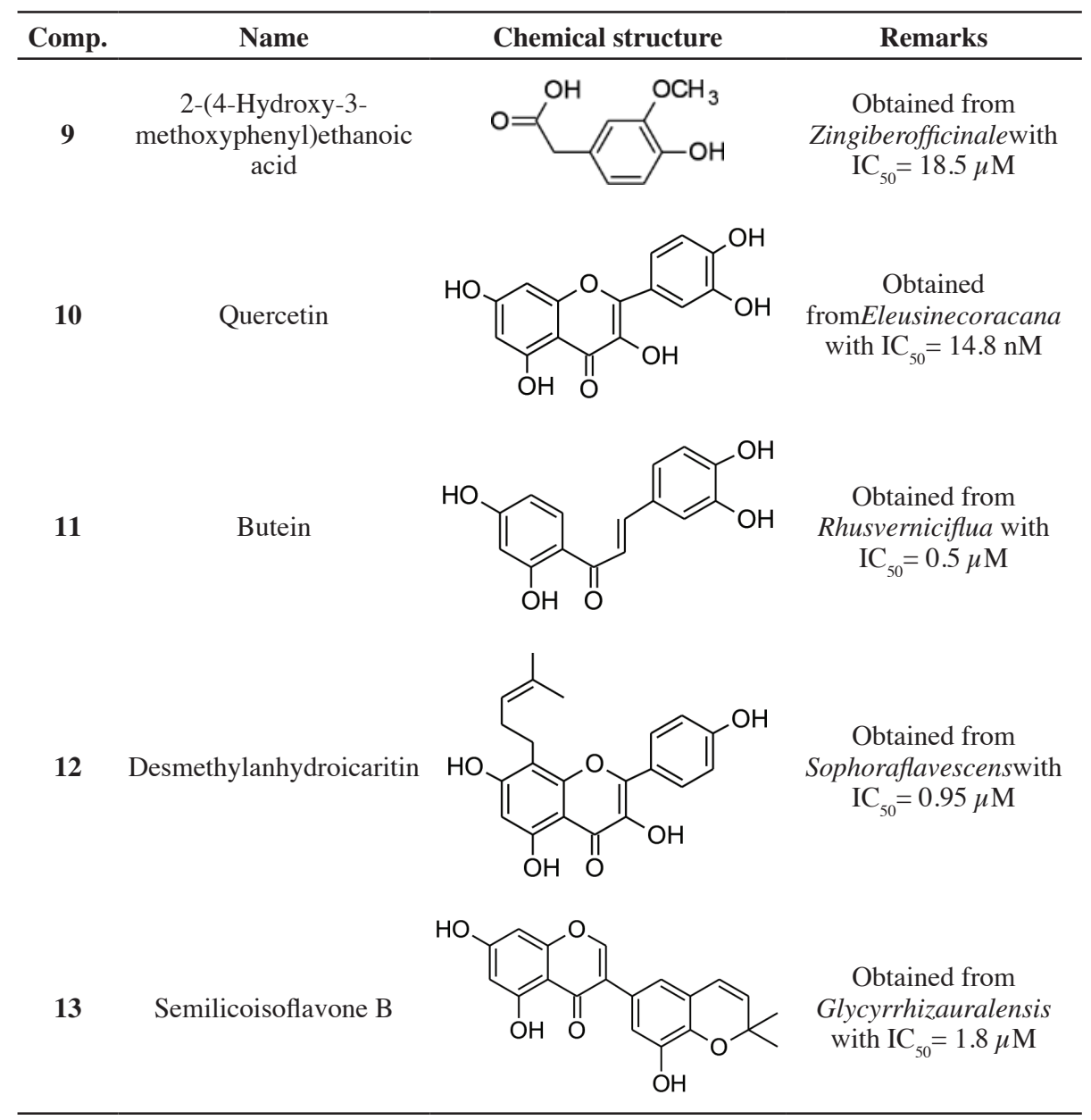

Molecular Docking Evaluation of Some

Natural Phenolic

Compounds as

Aldose Reductase

Inhibitors

for Diabetic

Complications

In this study 13 different natural phenolic compounds were selected for molecular docking studies. The drug-likeness properties including molecular weight, partition coefficient i.e., log P, hydrogen bond donors i.e., HBD, and hydrogen bond acceptors i.e., HBA were computed for the selected natural phenols. Most of the compounds selected for in silico studies showed drug-like properties as contrived by Lipinski's rule of five (presented in Table 2). All the selected natural phenolic molecules were docked in the active site of human AR protein (PDB entry: 4LBS). Most of the compounds showed appreciable binding pattern in the active site of AR protein as established by analyzing their bonding interactions in terms of $\mathrm{H}$-bond, hydrophobic interactions and $\Delta \mathrm{G}$ of the best docked poses (Table 2). 
Grewal, A.S. Sharma, N.

Singh, $\mathrm{S}$. Arora, S.
Table 2: Molecular properties, interacting amino acids, distance and $\Delta G$ of the selected natural phenolic compounds.

\begin{tabular}{|c|c|c|c|c|c|c|c|}
\hline Comp. & Mol. Wt.* & $\log P^{*}$ & HBA* & HBD* & $\begin{array}{c}\text { Interacting } \\
\text { amino acid (s) }\end{array}$ & 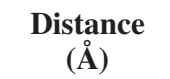 & $\Delta \mathrm{G}$ \\
\hline 1 & 316 & 1.6 & 7 & 4 & His 110, Trp 111 & $3.6,3.1$ & -8.6 \\
\hline 2 & 442 & 3.7 & 9 & 7 & $\begin{array}{c}\text { Tyr48, His } 110, \\
\text { Trp111 }\end{array}$ & $3.2,2.6,4.0$ & -8.9 \\
\hline 3 & 316 & 2.8 & 7 & 3 & Tyr48, His 110 & $4.2,3.2$ & -8.0 \\
\hline 4 & 475 & 2.0 & 11 & 4 & $\begin{array}{c}\text { Tyr48, His } 110, \\
\text { Trp111 }\end{array}$ & $3.8,3.3,3.0$ & -8.9 \\
\hline 5 & 286 & 2.4 & 6 & 4 & Trp111 & 3.8 & -8.1 \\
\hline 6 & 138 & 1.2 & 3 & 2 & Trp111 & 4.8 & -6.0 \\
\hline 7 & 258 & 3.4 & 4 & 3 & Tyr48 & 4.7 & -8.5 \\
\hline 8 & 368 & 4.0 & 6 & 2 & His110, Trp111 & $3.2,3.2$ & -8.2 \\
\hline 9 & 182 & 1.1 & 4 & 2 & $\begin{array}{c}\text { Tyr48, His } 110, \\
\text { Trp111 }\end{array}$ & $2.8,3.1,2.9$ & -9.8 \\
\hline 10 & 302 & 1.7 & 7 & 5 & Trp111 & 3.9 & -8.1 \\
\hline 11 & 272 & 3.4 & 5 & 4 & $\begin{array}{c}\text { Tyr48, His } 110, \\
\text { Trp111 }\end{array}$ & $3.2,2.8,3.2$ & -9.7 \\
\hline 12 & 368 & 4.0 & 6 & 4 & Trp111 & 2.9 & -7.2 \\
\hline 13 & 352 & 4.2 & 6 & 3 & Trp111 & 3.3 & -7.3 \\
\hline
\end{tabular}

*Mol. Wt., Log P, HBA, and HBD were calculated using MarvinSketch (2015).

Based on the lowest docking free energy and better binding interactions in the active site of AR protein, compounds 2, 4, 9, and 11 were further analyzed in details by PyMOL. The receptor-ligand complexes produced after docking of the selected natural phenolic compounds were analyzed in terms of H-bond interactions, hydrophobic interactions, binding free energy and orientation of the docked compounds in the active site of AR protein. These parameters show a chief role in the biological activity of a compound. The docked poses of the natural phenolic compounds were ranked based on the docking scores i.e. the lowest binding free energy and only the top ranked and best fitted conformations of the selected natural phenolic compounds were analyzed for the study. The overlay of the selected compounds $(2,4,9$, and 11) with that of reference inhibitor in the binding site of AR showed similar binding mode as that of the reference ligand (Figure 1). 

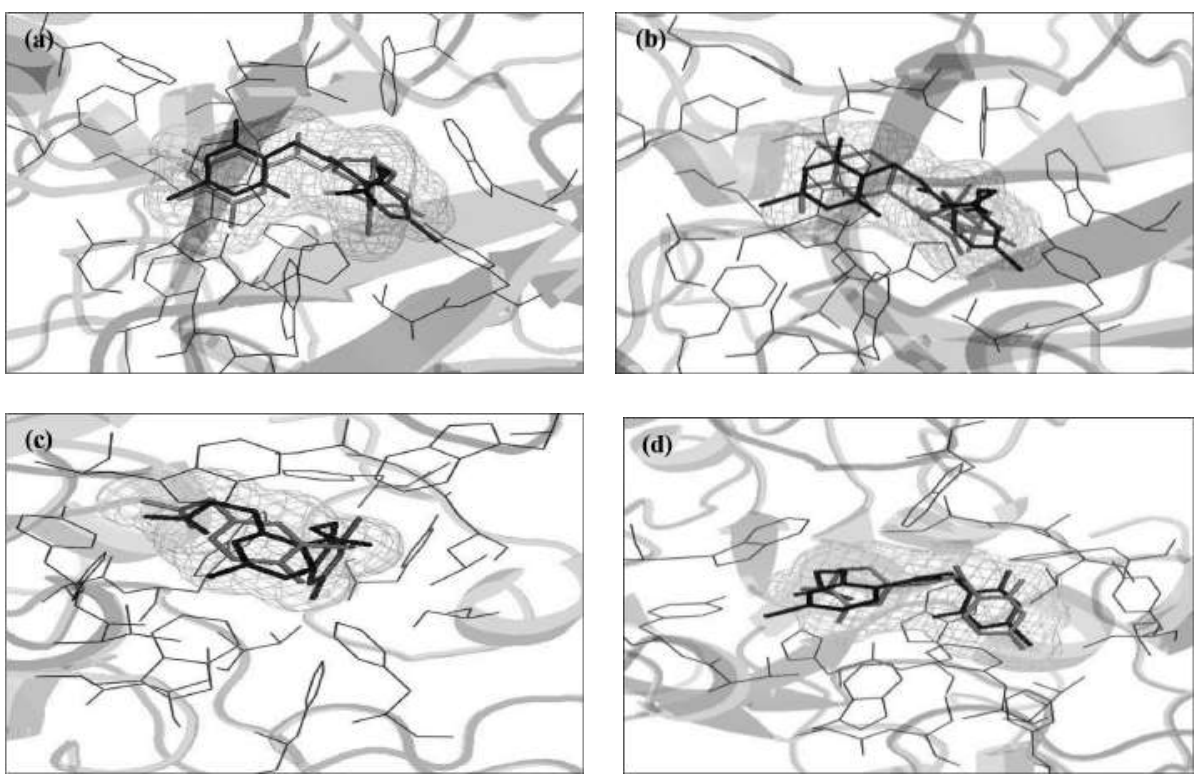

Molecular Docking Evaluation of Some

Natural Phenolic Compounds as

Aldose Reductase Inhibitors for Diabetic Complications

Figure 1: Overlay of compounds (black)2 (a), 4 (b), 9 (c) and 11 (d) with PDB ligand 4LBS (grey) in the binding site of AR protein.
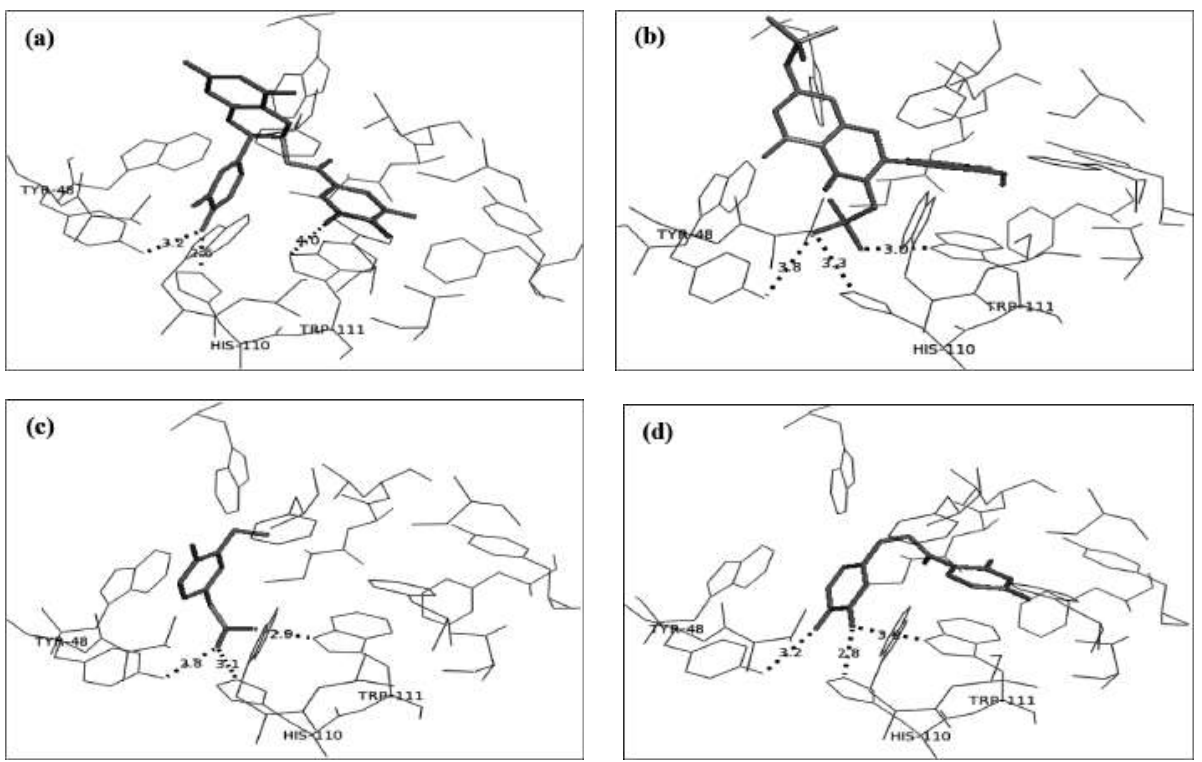

Figure 2: Docked pose showing H-bond interactions for the compounds 2 (a), 4 (b), 9 (c) and 11 (d) in binding site of AR protein. 
Grewal, A.S. Sharma, N. Singh, S. Arora, S.

The docked pose of compound $\mathbf{2}$ showed the H-bond interactions between the phenolic $\mathrm{OH}$ of compound $\mathbf{2}$ and $\mathrm{OH}$ of Tyr48, $\mathrm{NH}$ of His1 10 and $\mathrm{NH}$ of Trp111 in binding site of AR protein with H-bond distance of 3.2, 2.6 and 4.0 respectively (Figure 2a). The docked pose of compound $\mathbf{4}$ showed the $\mathrm{H}$-bond interactions between the alcoholic $\mathrm{OH}$ and $\mathrm{OH}$ of Tyr48, $\mathrm{NH}$ of His110 and $\mathrm{NH}$ of Trp111 in binding site of AR protein with $\mathrm{H}$-bond distance of 3.8, 3.3 and $3.0 \AA$ respectively (Figure 2b). The docked pose of compound 9 showed the H-bond interactions between the carbonyl and $\mathrm{OH}$ of Tyr48, $\mathrm{NH}$ of His 110 and $\mathrm{NH}$ of Trp111 in binding site of AR protein with H-bond distance of 2.8, 3.1 and $2.9 \AA$ respectively (Figure 2c). The docked pose of compound $\mathbf{1 1}$ showed the H-bond interactions between the phenolic $\mathrm{OH}$ and $\mathrm{OH}$ of Tyr48, $\mathrm{NH}$ of His110 and $\mathrm{NH}$ of Trp111 in binding site of AR protein with H-bond distance of 3.2, 2.8 and $3.2 \AA$ respectively (Figure $2 \mathrm{~d}$ ). This demonstrates that the selected natural phenolic compounds possess the functional groups required for effective binding with the active site residues when compared with the standard PDB ligand.

The best binding affinity of AR protein was found with the compounds 9 (2-(4-hydroxy-3-methoxyphenyl)ethanoic acid) and $\mathbf{1 1}$ (butein) in the complex of AR with binding free energy of $-9.8 \mathrm{kcal} / \mathrm{mol}$ and $-9.7 \mathrm{kcal} / \mathrm{mol}$, respectively. Other natural phenolic compoundssuch as compounds 2 (epicatechingallate) and 4 (isorhamnetin-3,7-disulfate) also represent good binding affinity with AR protein as indicated in Table $\mathbf{2}$. All these docking results and overlay of docked natural phenols with the PDB ligand 4LBS revealed that the selected natural phenols have a potential to inhibit AR enzyme.

\section{CONCLUSION}

Molecular docking studies using AutoDock vina and AutoDock Tools was performed to explore the binding mechanism of the selected natural phenolic compounds with AR enzyme. In the present molecular modeling study, results clearly demonstrated that the selected natural phenolic compounds have a similar binding sites and interactions with AR as those of the synthetic drug taken for the study and prove that dietary flavonoids (phenolic compounds) may possess properties useful for the control of diabetic complications. Thus in silico study is actually an added advantage to screen the AR inhibition and natural phenolic compounds may serve as useful leads for the synthesis of clinically useful and safe inhibitors of AR for therapeutics of diabetic complications. The results of docking study revealed that 2-(4-hydroxy-3methoxyphenyl)ethanoic acid and 11 (butein) have strongest binding with the AR protein with binding free energy of $-9.8 \mathrm{kcal} / \mathrm{mol}$ and $-9.7 \mathrm{kcal} / \mathrm{mol}$, respectively. Structural modifications and further studies on these natural 
phenolic compounds are required to develop safe and potent AR inhibitors for the management of various diabetic complications.

\section{REFERENCES}

[1] American Diabetes Association(2014) Diagnosis and classification of diabetes mellitus. Diabetes Care, 37, S81-S90. https://doi.org/10.2337/dc14-S081

[2] Berman, H. M., Westbrook, J., Feng, Z., Gilliland, G., Bhat, T. N., Weissig, H., et al. (2010) The protein data bank. Nucleic Acids Research, 2000; 28(1):2 35-242. https://doi.org/10.1093/nar/28.1.235

[3] Brownlee, M. (2001) Biochemistry and molecular cell biology of diabetic complications. Nature, 414, 813-820. https://doi.org/10.1038/414813a

[4] Cade, W. T. (2008) Diabetes-related microvascular and macro vascular diseases in the physical therapy setting. Physical Therapy, 88, 1322-1335.

https://doi.org/10.2522/ptj.20080008

[5] Chethan, S., Dharmesh, S. M., \& Malleshi, N. G. (2008) Inhibition of aldose reductase from cataracted eye lenses by finger millet (Eleusinecoracana) polyphenols. Bioorganic \& Medicinal Chemistry, 16, 10085-10090.

https://doi.org/10.1016/j.bmc.2008.10.003

[6] Chung, S. S., \& Chung, S. K. (2005) Aldose reductase in diabetic microvascular complications. Current Drug Targets, 6, 475-486.

https://doi.org/10.2174/1389450054021891

[7] Cumbie, B. C., \& Hermayer, K. L. (2007) Current concepts in targeted therapies for the pathophysiology of diabetic microvascular complications. Vascular Health and Risk Management, 3, 823-832.

[8] Forbes, J. M., \& Cooper, M. E. (2013) Mechanisms of diabetic complications. Physiological Reviews,93,137-188.https://doi.org/10.1152/physrev.00045.2011

[9] Fuente, J. A., \& Manzanaro, S. (2003) Aldose reductase inhibitors from natural sources. Natural Product Reports, 20, 243-251. https://doi.org/10.1039/b204709h

[10] Goodarzi, M. T.,Zal, F., \& Malakooti, M. (2006) Inhibitory activity of flavonoids on the lens aldose reductase of healthy and diabetic rats. ActaMedicaIranica, 44, 41-45.

[11] Grewal, A. S., Sekhon, B. S., \& Lather, V. (2014) Recent updates on glucokinase activators for the treatment of type 2 diabetes mellitus. Mini Reviews in Medicinal Chemistry, 14(7), 585-602. https://doi.org/10.2174/1389557514666140722082713

[12] Grewal, A. S., Bhardwaj, S., Pandita, D., Lather, V., \& Sekhon, B. S. (2016) Updates on aldose reductase inhibitors for management of diabetic complications and non-diabetic diseases. Mini Reviews in Medicinal Chemistry, 16(2), 120-162. https://doi.org/10.2174/1389557515666150909143737
Molecular Docking Evaluation of Some

Natural Phenolic

Compounds as

Aldose Reductase Inhibitors for Diabetic Complications

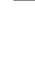


Grewal, A.S.

Sharma, N.

Singh, S.

Arora, S.
[13] Haraguchi, H., Ohmi, I., Sakai, S., Fukuda, A., Toihara, Y., Fujimoto, T., et al. (1996) Effect of Polygonumhydropiper sulfated flavonoids on lens aldose reductase and related enzymes. Journal of Natural Products, 59, 443-445.

https://doi.org/10.1021/np9601622

[14] International Diabetes Federation. (2013) IDF Diabetes Atlas, 6th Ed., Brussels, Belgium: International Diabetes Federation.

[15] Jain, S. V., Bhadoriya, K. S. \& Bari, S. B. (2012) QSAR and flexible docking studies of some aldose reductase inhibitors obtained from natural origin. Medicinal Chemistry Research, 21:1665-1676.

https://doi.org/10.1007/s00044-011-9681-6

[16] Jung, H. A., Yoon, N. Y., Kang, S. S., Kim, Y. S., \& Choi, J. S. (2008) Inhibitory activities of prenylated flavonoids from Sophoraflavescens against aldose reductase and generation of advanced glycation endproducts. Journal of Pharmacy \& Pharmacology, 60, 1227-1236. https://doi.org/10.1211/jpp.60.9.0016

[17] Kato, A., Higuchi, Y., Goto, H., Kizu, H., Okamoto, T., Asano, N., et al. (2006) Inhibitory effects of Zingiberofficinale Roscoe derived components on aldose reductase activity in vitro and in vivo. Journal of Agricultural and Food Chemistry, 54, 6640-6644. https://doi.org/10.1021/jf061599a

[18] Kohei, K. (2010) Pathophysiology of type 2 diabetes and its treatment policy. Japan Medical Association Journal, 53, 41-46.

[19] Lee, E. H., Song, D. G., Lee, J. Y., Pan, C. H., Um, B. H., \& Jung, S. H. (2008) Inhibitory effect of the compounds isolated from Rhusverniciflua on aldose reductase and advanced glycation endproducts. Biological and Pharmaceutical Bulletin, 31, 1626-1630. https://doi.org/10.1248/bpb.31.1626

[20] Lee, Y. S., Kim, S. H., Jung, S. H., Kim, J. K., Pan, C. H., \& Lim, S. S. (2010) Aldose reductase inhibitory compounds from Glycyrrhizauralensis. Biological and Pharmaceutical Bulletin, 33, 917-921. https://doi.org/10.1248/bpb.33.917

[21] Lee, D. G., Lee, K. H., Park, K. W., Han, C. K., Ryu, B. Y., Cho, E. J., et al. (2015) Isolation and identification of flavonoids with aldose reductase inhibitory activity from Petasites japonicas. Asian Journal of Chemistry, 27(3), 991-994. https://doi.org/10.14233/ajchem.2015.17845

[22] Logendra, S., Ribnicky, D. M., Yang, H., Poulev, A., Ma, J., Kennelly, E. J., et al. (2006) Bioassay-guided isolation of aldose reductase inhibitors from Artemisia dracunculus. Phytochemistry, 67, 1539-1546. https://doi.org/10.1016/j.phytochem.2006.05.015

[23] MarvinSketch version 15.9.21. ChemAxon Ltd., http://www.chemaxon.com, 2015.

[24] Miteva, M. A., Guyon, F., \& Tufféry, P. (2010) Frog 2: Efficient 3D conformation ensemble generator for small compounds. Nucleic Acids Research, 38, W622-627. https://doi.org/10.1093/nar/gkq325 
[25] Mohan, V., \& Anbalagan, V. (2013) Expanding role of the Madras Diabetes Research Foundation - Indian Diabetes Risk Score in clinical practice. Indian Journal of Endocrinology and Metabolism, 17, 31-36.

https://doi.org/10.4103/2230-8210.107825

[26] Morikawa, T., Xie,H., Wang, T., Matsuda,H., \& Yoshikawa,M.(2008) Bioactive constituents from Chinese natural medicines. XXXII. aminopeptidase N and aldose reductase inhibitors from Sinocrassulaindica: structures of sinocrassosides $\mathrm{B}(4), \mathrm{B}(5), \mathrm{C}(1)$, and $\mathrm{D}(1)-\mathrm{D}(3)$. Chemical and Pharmaceutical Bulletin, 56, 1438-1444. https://doi.org/10.1248/cpb.56.1438

[27] Morris, G. M., Huey, R., Lindstrom, W., Sanner, M. F., Belew, R. K., Goodsell, D. S., et al. (2009) Autodock4 and AutoDockTools4: automated docking with selective receptor flexiblity. Journal of Computational Chemistry, 16, 2785-2791. https://doi.org/10.1002/jcc.21256

[28] Murata, M., Irie, J., \& Homma, S. (1994) Aldose reductase inhibitors from green tea. Journal of Food Science and Technology, 27, 401-405.

https://doi.org/10.1006/fstl.1994.1085

[29] Muthenna, P., Suryanarayana, P., Gunda, S. K., Petrash, J. M., \& Reddy, G. B. (2009) Inhibition of aldose reductase by dietary antioxidant curcumin: mechanism of inhibition, specificity and significance. FEBS Letters, 583, 3637-3642.

https://doi.org/10.1016/j.febslet.2009.10.042

[30] Nakai,N.,Fujii,Y.,Kobashi,K.,\& Nomura,K.(1985) Aldose reductase inhibitors: flavonoids, alkaloids, acetophenones, benzophenones, and spirohydantoins of chroman. Archives of Biochemistry and Biophysics 1985; 239:491-496. https://doi.org/10.1016/0003-9861(85)90717-9

[31] Oates,P.J.(2008) Aldosereductase,stillacompellingtargetfordiabetic neuropathy. Current Drug Targets, 9, 14-36. https://doi.org/10.2174/138945008783431781

[32] Okada, Y., Miyauchi, N., Suzuki, K., Kobayashi, T., Tsutsui, C., Mayuzumi, K., et al. (1995) Search for naturally occurring substances to prevent the complications of diabetes. II. Inhibitory effect of coumarin and flavonoid derivatives on bovine lens aldose reductase and rabbit platelet aggregation. Chemical and Pharmaceutical Bulletin, 43, 1385-1387. https://doi.org/10.1248/cpb.43.1385

[33] Olokoba, A. B., Obateru, O. A., \& Olokoba, L. B. (2012) Type 2 diabetes mellitus: a review of current trends. Oman Medical Journal, 27, 269-273.

https://doi.org/10.5001/omj.2012.68

[34] Suzen, S., \& Buyukbingol, E. (2003) Recent studies of aldose reductase enzyme inhibition for diabetic complications. Current Medicinal Chemistry, 10, 1329-1352. https://doi.org/10.2174/0929867033457377

[35] Tomás-Barberán, F. A., López-Gómez, C., Villar, A., \& Tomás-Lorente, F. (1986) Inhibition of lens aldose reductase by Labiatae flavonoids. PlantaMedica, 3, 239-240. https://doi.org/10.1055/s-2007-969135
Molecular Docking Evaluation of Some

Natural Phenolic

Compounds as

Aldose Reductase Inhibitors for Diabetic Complications 
Grewal, A.S. Sharma, N. Singh, $\mathrm{S}$. Arora, S.
[36] Trott, O., \& Olson, A. J. (2010) AutoDock Vina: improving the speed and accuracy of docking with a new scoring function, efficient optimization and multithreading. Journal of Computational Chemistry, 31, 455-461.

[37] Wild, S., Roglic, G., Green, A., Sicree, R., \& King, H. (2004) Global prevalence of diabetes: estimates for the year 2000 and projections for 2030. Diabetes Care, 27, 1047-1053. https://doi.org/10.2337/diacare.27.10.2569-a

[38] Yabe-Nishimura, C. (1998) Aldose reductase in glucose toxicity: a potential target for the prevention of diabetic complications. Pharmacological Reviews, $\mathbf{5 0}, 21-33$.

[39] Zhang, C. L., Wang, Y., Liu, Y. F., Liang, D., Hao, Z.Y., Luo, H., et al. (2016) Two new flavonoid glycosides from Iris tectorum. Phytochemistry Letters, 15, 63-65. https://doi.org/10.1016/j.phytol.2015.11.012 